\title{
Balconies, analysis of constructive technology current state and foresight of new industrial development
}

\author{
L. Sierra \& J.L1. Zamora \\ Laboratory of Innovation and Technology in Architecture (LiTA), Universitat Politècnica de Catalunya \\ (UPC)
}

\begin{abstract}
Despite being an essential part of the Mediterranean facade, the balcony has been relegated to a background in the recent technological evolution of the envelope of the buildings constructed in Spain since the end of the 20th century. In the same way that technician solutions for roofing and facades have been intensively developed, is the balcony destined to be industrialized as any other element? If so, could it become industrialized? And how should it be? Who must generate it?
\end{abstract}

\section{INTRODUCTION}

The balcony has been, and still is, an essential architectural element in the configuration of the residential buildings in the Mediterranean tradition, with a strong representativeness for users and architects. However, it is not apparently perceived an innovative concern of the same intensity that has characterized the technological research of the facade since the end of the 20th century. Over the last years in Spain, the constructive development of the architectural envelope has focused mainly on the evolution of the typology of the lightweight ventilated facade, which has consolidated new concepts based on a continuous skin that surrounds the whole building. This continuity seems incompatible with the current relation with balconies, as these are elements that stand out in cantilever drilling it, breaking this new protective and filter skin. In this way, many of the recent buildings facades are projected preferably with light-flat surfaces without bulges.

However, the balcony cannot be left behind, because in addition to the inherent contributions of the element itself and its compositional load, it incorporates a remarkable potential that should be especially considered in the upcoming years for a more sustainable architecture: it allows life on the outside of the building, produces shadows on itself, minimizes the action of rain and wind, it is a good vegetal container, etc. Thus, it seems that its use is being reassumed and will be necessary, therefore, to merge its incorporation with the technological advances of the facade. Also, a growing social and regulatory restriction has introduced new requirements such as fire safety, higher passive climate control, demands against the wind, etc. that could be tackled with a technological-conceptual evolution of the balcony.

Moreover, there is a large fleet of buildings with balconies that, due to his condition of item continuously exposed to the weather (changes of temperature, presence of water, etc.), have experienced over time obvious damages, undermining its durability (corrosion, leakage of water, landslides, stains, degradation of the coating, etc.). Up to the present moment we have analysed these issues above all in order to prevent future diseases and new products and systems have been introduced to solve specific problems, but a comprehensive solution of the balcony which satisfies all outstanding requirements has not been addressed. The rehabilitation of balconies should not only be confined to superficial repairs, but it has to cover a wider scope as the comprehensive rehabilitation of the element and the revaluation of the building by the addition of 
balconies to its facade, taking into account the possibility of improvement or replacement in the future.

It is appropriate, therefore, to outline the basis for the technological evolutions of this element with the double aim of optimize its production and upgrade its adjustment to recent expectations and needs: adjustment of cost, reducing environmental impact, ease of maintenance, improved joints and facilitate fits with other elements of the building, etc.

In this sense, everything indicates that the current trend of the construction sector, with most of the agents involved in this process, leads to industrialization. Gradually, buildings have been incorporating precast elements more or less systematized but, so far, nobody seems to worry about how this capability of streamlining really affects the balcony. In the same way technical solutions for roofing, walls and voids have been intensively developed, the balcony seems destined to an industrialization of its construction.

\section{DESCRIPTIVE-TECHNOLOGICAL ANALYSIS}

\subsection{Current situation}

To approach possible ways of future developments of the balcony, an analysis of the current situation and the trends that will affect its evolution should first be conducted.

A first glance shows the strong rooting in Spain of cantilever reinforced concrete construction. This method ensures a high-rigid embedment of the balcony with the main structure, as it is the outward extension of the inner slab, but, on the other hand, this practice involves problems such as thermal bridges, leaks, deficiencies in the sealing, etc. However, this solution so apparently consolidated has no more than 100 years. Let see this through a reflection on the historical evolution of the technical constitution of the balconies and overhangs in Catalonia.

Already in the 17th century, a revolution was carried out in the conception of balcony, popularizing its use by the addition of this item to existing buildings, embedding profiles of forged iron in the wall's facade in order to support a platform, and covering the ceiling of this platform with ceramic pieces decorated by the soffit.

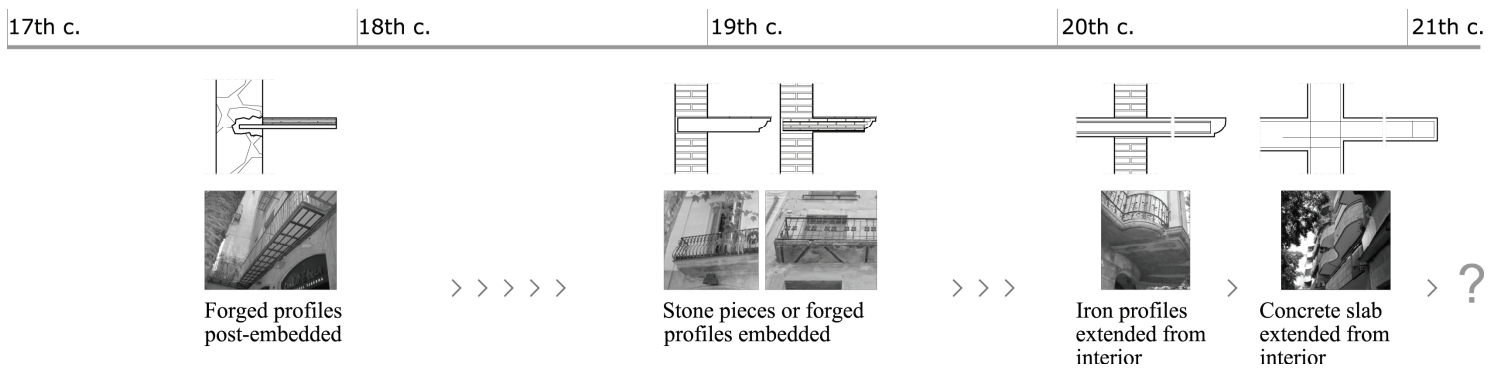

Figure 1. Incorporation of the balconies at a building in 7 Lledó st. (Barcelona) on the XVIIth c.

Later, this solution gave way to stone pieces, also embedded in the facade with a simultaneously supporting and wall-enclosure function. But it is not until the mid-20th century that the structural capacity of the steel and concrete lead to the pretension of major span and to the proliferation of a new structural mechanism for the implementation of balconies: the projection cantilever from the interior beams in continuity with the outside. The historical evolution of the balcony has been conducted through interference and mutual influences among different factors (technological innovation, architectural context and new regulatory requirements), linked to specific aspects of the site (available technology, constructive tradition, seismic features, weather, etc.). Thus, the evolutionary path of the balcony is filled with comings and goings and, maybe, now is time to re-think the technology appropriate to the current moment.

Coming back to present, we recently began to detect emerging solutions and architects' concerns to approaches of balconies executed independently of the general building's structure and connected to it via different mechanisms. From the definition of balcony as the open space of relationship between the interior and exterior situated on the facade, current balconies have been 
laid down according to the position between main structural level, the balcony itself and the position of the closuring plan:

- Outside over hanged space onwards of the facade plane. It consists in the simple extension of the interior slab. Although it is the conventional method for the implementation of balconies in Spain, it has no sense when one considers that the requirements and conditions set up for the outside balcony and the interior slabs of separation between floors are totally different. Balconies have no acoustic requirements, do not need mass and must not be insulated thermally as space, although do require thermal bridge control, protection and maintenance.

- Projected space with external enclosure. A progressive separation between the successive layers of lightweight ventilated facade has led to the emergence of an intermediate space that ends up filled. The structural plan of the building is kept inside and the facade itself expands to create an outdoor living space between the inner and the outer skins.

- Inside space. It is formed from backing freely the facade line in certain sections, towards the interior of the building, keeping the structural level on the outside, and modelling a compact overall volume, without giving up on a space of relationship with the outside. This space works as energy exchanger and is protected by the building itself. However, the disadvantages associated with thermal bridge remain, as the slab is exposed to the weather.

- Outside added item. Despite not being a common solution, in nowadays it has been detected a noticeable concern by designers to generate conceptually more advanced solutions. However, these formal wills linked to technical innovations designed in phase of competition, just end up diluting at the Definitive project and materializing with conventional methods of insitu reinforced concrete. All the examples that have been observed of this architectural type materialize from light structural steel solutions, manufactured in workshop as a preliminary design by the architect. Conceptually, this solution is associated with the emerging idea that the balcony floor does not share the interior floor requirements and therefore not necessarily be the same extension. The introduction of prefabricated systems requires re-thinking traditional methods of construction.

- Self-supporting outdoor added item. This balcony scheme is the most appropriate for rehabilitation projects that require not adding loads to the existing building.

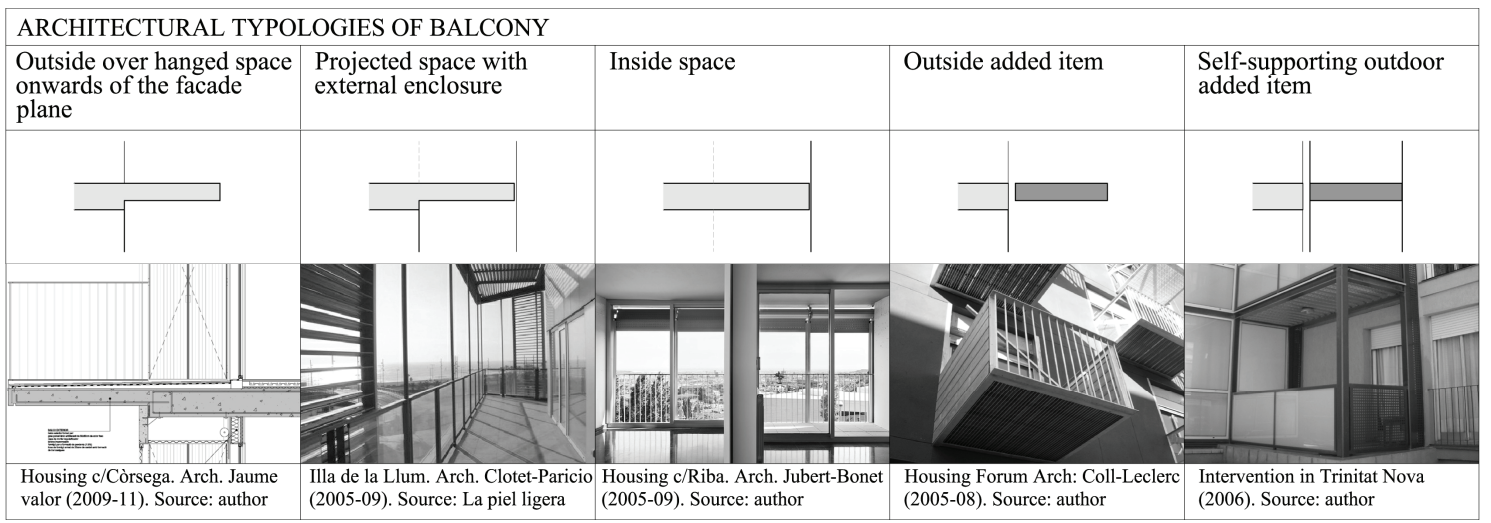

Figure 2. Summary table of balcony architectural types based on the relationship between main structural level, the balcony itself and the position of the closuring plan.

There is not, therefore, a single architectonic-technological type of balcony, but that our age is probably characterized by the search of a constructive model that satisfies as many requirements. So, each type has specific characteristics that require different evolution methods.

Internationally, the range of resources is much wider than in Spain. Structurally it is experimenting with approaches such as lattices of major proportions, placed at the top of the building from where the balconies are hung, tensors promptly placed containing the isolated balcony, or simply by inserting it into the façade, and technical solutions as the direct anchor of the balcony to the slab of the building or through the collaboration of a railing with structural function or supported by suspenders are regularly made. In fact, those are approaches which in Spain seems 
to start appearing in project-wide experimentation phase but do not just materialize constructively. This discrepancy is due on the one hand to, among many other aspects, that in the rest of Europe there is a Nordic tradition linked to assembly solutions based on semi-components, that is a more industrialized construction solutions, and on the other hand a greater concern, justified by variations in temperature, for the hydrothermal behaviour of the envelope that requires specific solutions to thermal transfers.

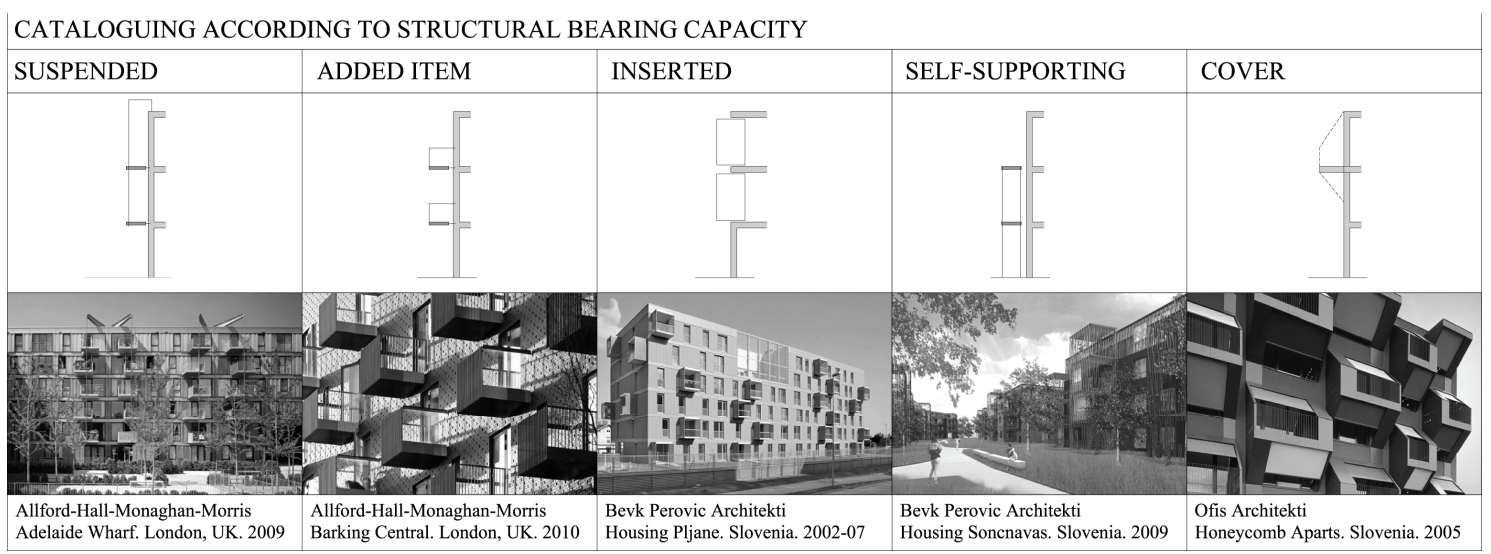

Figure 3. Some examples of technical solutions for balconies use outside Spain: suspended, element addition, inserted, self-supporting or a simply cover.

\subsection{Levels of prefabrication}

The overall level of building industrialization in Spain is lower than in other European countries. Although we can find products or systems to deal with specific issues, it seems that the industry of construction, being highly sectioned, fails to address the problem of the balcony as a whole. However, beyond of the Iberian Peninsula, a significant number of companies can be founded, offering technical comprehensive balconies systems that can be classified according to their level of prefabrication, that is, the amount of operations to be performed in situ in relation to the previous process already developed in the workshop. According to this approach, the following categories may be stating:

- Basic level of prefabrication (LP0) fits the complete performance on site, a conventional construction which projects the indoor slab as a cantilever, based on shuttering and industrialized struts for in situ concrete, and incorporating in some cases for-lost elements.

- Initial level of prefabrication (LP1) already incorporates elements that ensure compliance with certain specific requirements. It is the case, for example, of linear elements placed on the edge of the slab with dual function: to connect the balcony with the building and to respond to the problems associated with the thermal bridge. Despite being an industrial product, still requires a relatively craft work start-up. It is a widely used resource in Northern Europe, with a large number of companies that marketed it.

- Advanced level of prefabrication (LP2) corresponds to the products that offer partial balcony prefabrication either by primary elements (structural base) or secondary (handrails). There is currently a wide range of Spanish companies which are engaged in modular railings, designed to be installed on cantilevers executed with in situ reinforced concrete, so just have to install the railing to complete the balcony.

- Integral prefabrication level (LP3) corresponds to the complete products, whether they are finished components (installation on site of the balcony finished in workshop with the consequent transport of the three-dimensional volume) or partial (from the assembly on site of twodimensional prefabricated elements). 


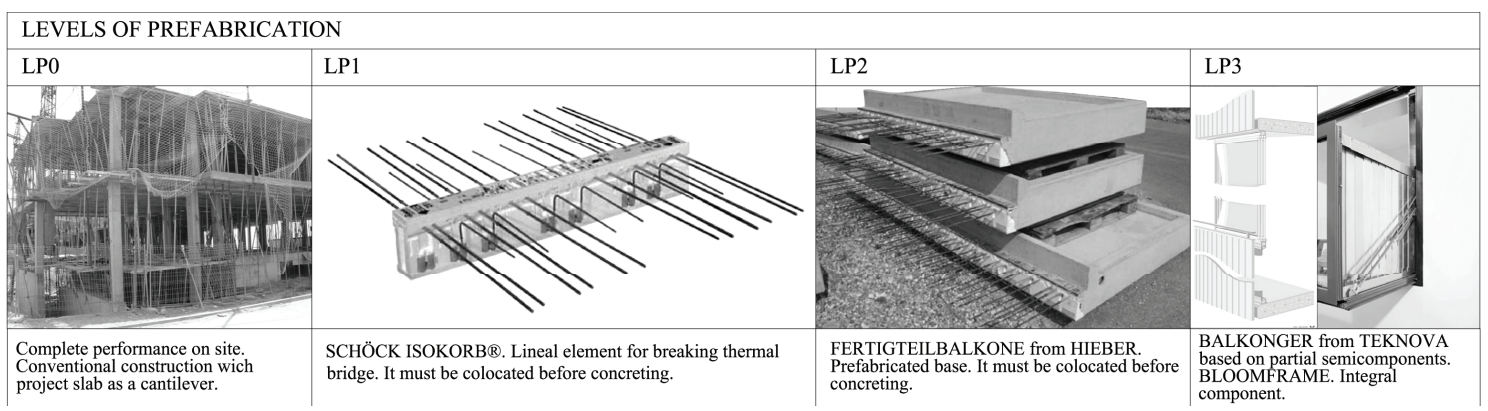

Figure 4. Categorization of the levels of prefabrication based on the number of operations to be carried out in situ in relation to the previous process already developed in the workshop.

Obviously, each level of prefabrication is associated to a number of advantages and disadvantages. Therefore, depending on the nature of each project or intervention, may be more efficient a system with a greater or lesser level of prefabrication. It is risky opt for one or another level in a widespread way. However, this categorization gives us clues of how the industrialization of balcony can be approached.

\section{PROPOSITIVE ANALYSIS}

The construction sector is showing a growing concern by the majority of stakeholders (architects, industrial, promoters, etc.) about finding solutions based on prefabricated elements that fit costs, contingencies, works on site, and improve the final quality of the finishes and, ultimately, efficiency. However, there has not been implemented an industrialized system for balconies, at least not as a whole. Therefore, the first question to face is to determine which have probably been the obstacles which hampered the industrialization of this element, to then establish whether these obstacles have been overcome, if they can be overcome, or even, if have to be overcome. The difficulties, in Spain, of implementation of new industrialized balconies systems focus on the proper functioning of the sector, in the fragmentation within the construction field affecting a sector not cohesive where any new industrial insertion attempt is rejected. The balcony, placed on the border between the industry of the facades, the woodwork and structure, seems not to have found its place.

The industry of the balcony has been slowed down by multiple impairments; however, all of them seem to be socio-economic. Everything points to the technology needed for industrial processes, suitable materials, computer programs, etc. are available but it is necessary to overcome a certain attitude towards industrialization. Therefore, it is technologically feasible to propose solutions industrialized for balconies.

\subsection{Opportunity Sector}

At the time of implementing new solutions in the market, industry must be prepared to carry out and be able to do so. Probably the main handicap with which the balcony faces in relation to its technological evolution, is that there are not companies specializing in this field, i.e., the figure of "balconist" does not exist. Faced with this challenge, there are several options: to create a new industrial profile, or an existing sector incorporates it in its production, or a consortium of companies to develop the balcony as element to industrialize is generated. But who could promote this function? What stage of the intervention would fit better the renewal of the balcony, taking into account that combines different particularities of other elements and that is at a point of technical border in the building?

To answer these questions, it is necessary to consider a number of aspects previously:

- Required availability of technology (machinery, tools, processors, etc.)

- Types of elements that could be integrated: primary (resistance), secondary (finishes), tertiary (accessories) or all of them. In other words, a finished product. 
- The industrial ease to join the process of work or, if it already belongs to it, identify at what stage in relation to the placement of the balcony.

- Level of customization requested: cutting to custom or pre-set dimensions, in-time or instock production. To what extent can the product be varied?

- Technical requirements: structural, hydrothermal behaviour, weather durability, etc.

- Logistical aspects, of collection of material, etc. Availability of space.

- Knowledge of joints of prefabricated elements and mounting systems.

According to these aspects becomes clear that the in advance more convenient subsectors, such as metal hardware, have some limitations in terms of finishes and thermal comfort requirements, although in favour they already incorporate in its usual procedures high standards of safety and control processes. Meanwhile, the reinforced concrete prefabricators have experience in logistics and transportation optimization but reduce their level of customization. In this sense, there are other available manufacturers that may not have a so obvious or direct relationship with the construction of balconies, but that must be taken into account from a wider opportunity vision.

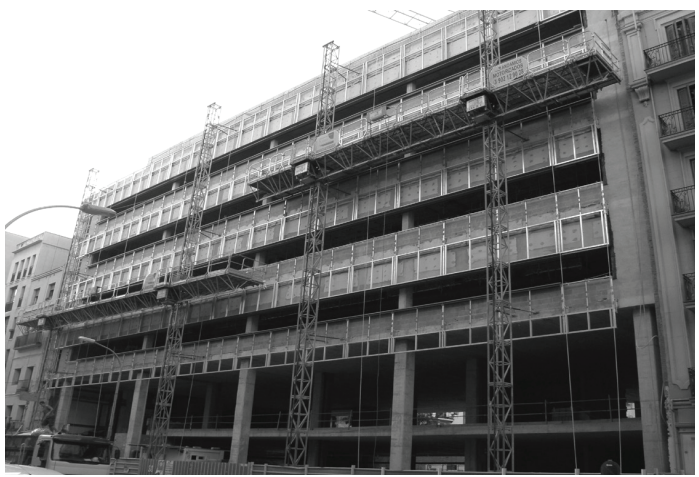

Figure 5. The image of a scaffold structure recalls the provision of balconies in a metal framework.

\subsection{Procedure to generate proposals}

Firstly, an analysis using the SWOT method of the industrialization of the balconies allows establishing mechanisms for a further industrial development. Detecting weaknesses allows getting to know mechanisms to overcome them. Then, the strengths also must be boosted. In this specific case, using lightweight systems with fastenings integrated into the set, a high level of customization, either by partial semi-components or by a common effort from the beginning, optimizing transport, integrating existing or potential requirements, etc.

\begin{tabular}{|c|c|c|}
\hline 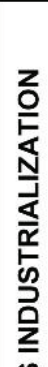 & $\begin{array}{l}\text { Strengths: } \\
\text { - Optimization of resources and reduction of waste } \\
\text { generation. } \\
\text { - Resolve outstanding requirements such as the thermal } \\
\text { bridge. } \\
\text { - It can be improved and/or replaceable. } \\
\text { - Optimization of time on site. } \\
\text { - Removable and reusable. } \\
\text { - Greater guarantee of quality } \\
\text { - Greater safety at work }\end{array}$ & $\begin{array}{l}\text { Weaknesses: } \\
\text { - Weight } \\
\text { - Loss of rigidity in the fix } \\
\text { - Possible limitations at clientalization level } \\
\text { - Bad optimization of 3D object transport }\end{array}$ \\
\hline 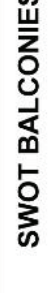 & $\begin{array}{l}\text { Opportunities: } \\
\text { - Take advantage of the moment of crisis to generate } \\
\text { innovation. } \\
\text { - Incorporate values related to sustainability and new social } \\
\text { and regulatory requirements. } \\
\cdot \text { Building Revaluation through the addition or replacement } \\
\text { of balconies. } \\
\text { - It's possible to incorporate facilities. }\end{array}$ & $\begin{array}{l}\text { Threats: } \\
\text { Rigidity of the construction sector. } \\
\text { - Other industrialists, as concrete companies (lose scope). } \\
\text { - Manufacturers of railing on a small scale. }\end{array}$ \\
\hline
\end{tabular}

Figure 6. Analysis through SWOT method about the convenience of balcony industrialization. 
Through the interrelation of the factors influencing the incorporation of a product on the market, it is possible to establish mechanisms for its development.

On the one hand, possible solutions are discriminated with inputs linked to associated technology: ideal material to build it, industrial with capacity to carry it out, phase of the construction process in which to place the balcony, method of transport optimized, ensuring customization, in site anchoring mechanisms and closing of the cycle of life. Then there are other specific inputs of the balcony, more related to requirements of the item: treatment of the thermal bridge, evacuation and collection of water.

Thus, we define a procedure that leads not to a single solution, but can produce different alternatives on each of the decisions taken on the basis of the needs and requirements relating to each profile balcony that arises. Below are proposed 4 possible scenarios or profiles.

- Profile 1 XS: corresponds to the urban balcony, small size, with a timely use of relationship with the outside. Suitable for an urban context of narrow streets and high density.

- Profile 2 XL: balcony with bigger dimensions (extra-large) that could incorporate programmatic functions and would have one higher surface.

- Profile 3 XXL: "extralong". It would allow continuous balconies by the addition of isolated elements.

- Profile 4: rehabilitation. Suitable for the revaluation of buildings from the addition of new balconies.

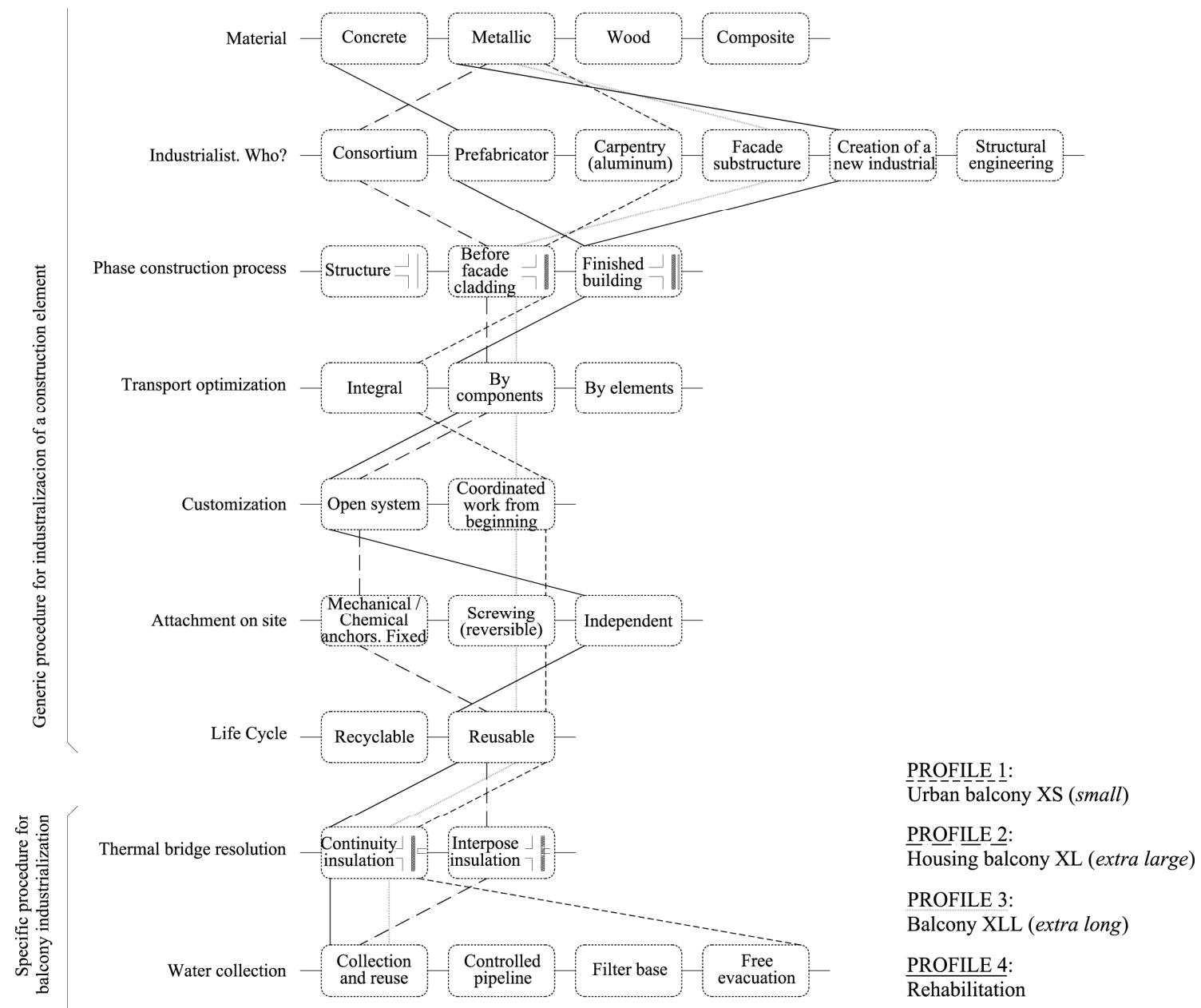

Figure 7. Procedure to generate proposals from established inputs. 
Obviously, each profile can take different paths depending on the options of the project. In practice, there may be other variables such as proximity or remoteness of the factory with the plot, the availability of material, the link between companies, etc.

Thus, there isn't a default industrialized solution, as it will depend on the type of project, the possibilities of manufacturing, of available material, the level of prefabrication of the solution, etc. It should also be considered aspects such as the structural relationship between the balcony and the building and other short-term aspects as the conditions of transport, mounting, the possible replacement of parts or improvement, deconstruction, even reuse.

\section{CONCLUSIONS}

We must search new technological paths for the construction of balconies within the framework of an envelope industrialized as a whole. The balcony, placed on the border between the industry of the facades, the woodwork and the structure, seems to have not found its place yet.

The evolution of the balcony should allow the introduction of new requirements and demands unresolved, and the industrialization is presented as a tool to optimize resources, both economic and energetic, providing a great number of advantages over conventional construction.

In the same way it happens in many other industries, the construction industry requires the possibility of customization. It has to be understood not as a massive repetition of a single element, but as generating systems or products adaptable to the needs. In this sense, if the definition of the element is done before entering the production chain, it will be possible to adapt the industrial processes to prevent future manipulations and, at the same time, will be a component to measure.

Mediterranean countries have a large park built in need of repair (degraded balconies), rehabilitation (in a broader sense - substitution, perfectibility-) and revaluation (addition of balconies). And all this within a framework of technified solutions.

An opportunity has been detected in the construction sector of incorporating industrialized balconies in relation to current buildings envelopes, with better performances and, in the same way, to respond to a more ambitious and complex approach of the rehabilitation of balconies in the framework of the integral renovation of the facade.

The industrial plot that has to develop it is not predefined so it can be approached from different flanks.

\section{REFERENCES}

De Aguila, A. 1986. La industrialización de la edificación de viviendas. $3^{a}$ edición revisada. Tomo 1 Sistemas. Madrid: Mairea Libros

Espadaler, A. \& Manent, R. 2007. Balcons de Barcelona. Un espai privat obert al públic. Barcelona: Ed. Institut Municipal del Paisatge Urbà i la Qualitat de Vida (IMPUiOV), Ajuntament de Barcelona.

González, J.M. et al. 2001. Alternativas a la construcción convencional de viviendas. Barcelona: Itec. Institut Català del Sòl. 2006-2009. Concurs d'Assistència Tècnica: habitatge protegit a Catalunya [91 actuacions, 4169 habitatges]. Barcelona: ed. InCaSol, Generalitat de Catalunya.

Pardal, M. 2009. Thesis: The inner sheet of ventilated facades, Barcelona: edicions UPC.

Paricio, A. 2001. Secrets d'un sistema constructiu. Barcelona: edicions UPC.

Pérez, S. 2009. Industrializar. Informes de la Construcción. Vol. 61 (513): 5-10.

Sarja, A. 1998. Open and industrialised building, London: New York: E \& FN Spon.

Sierra, L. 2012. El balcó. Un element industrialitzable?, Barcelona: Edicions UPC.

Zamora, J.L1. 1995. Diseño de fachadas ligeras: Manual de introducción al proyecto arquitectónico. Parets del Vallès: Hydro Building Systems. 